\title{
Application of loop analysis for evaluation of malaria control interventions
}

\author{
Junko Yasuoka ${ }^{1 *}$, Masamine Jimba ${ }^{1}$ and Richard Levins ${ }^{2}$
}

\begin{abstract}
Background: Despite continuous efforts and recent rapid expansion in the financing and implementation of malaria control interventions, malaria still remains one of the most devastating global health issues. Even in countries that have been successful in reducing the incidence of malaria, malaria control is becoming more challenging because of the changing epidemiology of malaria and waning community participation in control interventions. In order to improve the effectiveness of interventions and to promote community understanding of the necessity of continued control efforts, there is an urgent need to develop new methodologies that examine the mechanisms by which community-based malaria interventions could reduce local malaria incidence.

Methods: This study demonstrated how the impact of community-based malaria control interventions on malaria incidence can be examined in complex systems by qualitative analysis combined with an extensive review of literature. First, sign digraphs were developed through loop analysis to analyse seven interventions: source reduction, insecticide/ larvicide use, biological control, treatment with anti-malarials, insecticide-treated mosquito net/long-lasting insecticidal net, non-chemical personal protection measures, and educational intervention. Then, for each intervention, the sign digraphs and literature review were combined to analyse a variety of pathways through which the intervention can influence local malaria incidence as well as interactions between variables involved in the system. Through loop analysis it is possible to see whether increases in one variable qualitatively increases or decreases other variables or leaves them unchanged and the net effect of multiple, interacting variables.

Results: Qualitative analysis, specifically loop analysis, can be a useful tool to examine the impact of community-based malaria control interventions. Without relying on numerical data, the analysis was able to describe pathways through which each intervention could influence malaria incidence on the basis of the qualitative patterns of the interactions between variables in complex systems. This methodology is generalizable to various disease control interventions at different levels, and can be utilized by a variety of stakeholders such as researchers, community leaders and policy makers to better plan and evaluate their community-based disease control interventions.
\end{abstract}

Keywords: Qualitative analysis, Malaria control, Community-based intervention

\section{Background}

Malaria remains one of the most devastating global health threats. In spite of continuous efforts and recent rapid expansion in the financing and implementation of malaria control programmes, millions of people still suffer from a lack of access to preventive measures, diagnostic testing and quality-assured treatment [1]. The Global Malaria Eradication Campaign in the 1950s and 60 s failed due to its assumption that malaria eradication

\footnotetext{
* Correspondence: jyasuoka@post.harvard.edu

'Department of Community and Global Health, The University of Tokyo,

7-3-1 Hongo, Bunkyo-ku, Tokyo 113-0033, Japan

Full list of author information is available at the end of the article
}

could be achieved by a one-size-fits-all strategy rather than tailor-made interventions that take local contexts into account [2]. Yet current malaria control relies heavily on such a failed strategy, using a limited number of tools, particularly anti-malarial drugs and insecticidetreated mosquito nets/long-lasting insecticidal nets (ITN/LLIN), both of which have become less effective because of resistance [1]. Vector control follows a similar strategy and has not been successful either mainly because of continued heavy dependence on chemical spraying, which has led to vectors' resistance to insecticides $[3,4]$. Furthermore, the lack of intersectoral cooperation, interdisciplinary approaches and community 
participation has been impeding sustainability in malaria control efforts [5-7]. Consequently, these challenges have led to a growing interest in formulating new approaches for developing, delivering and maintaining malaria control, especially in areas with high and/or unstable transmission $[3,8,9]$.

When developing new strategies, possible consequences of each intervention need to be examined within a complex system. A majority of current efforts to plan and conduct interventions and to evaluate their effectiveness are narrowly focused on direct associations between a limited number of factors. For example, there has been a heavy reliance on insecticide to control malaria vectors mainly due to the belief in the single, direct aspect of the insecticide's impact (lethal effect) on the pest. However, it does not necessarily work that way for at least three reasons: 1) a decrease in the vector population can decrease the predator population by affecting the availability of food for the predators; 2) insecticide directly reduces the predators of the vector; and, 3) natural selection in the vector population rapidly builds up resistance to the insecticide [10]. Therefore, there is a need for a methodology that enables us to better understand complex systems, to examine the associations and correlations among a variety of factors involved, and to foresee how unexpected consequences might occur.

Furthermore, the methodology needs to be utilized not only by researchers, policy makers and programme and project implementers, but also by community members. Community participation is a key to the success of malaria control interventions at the community level, and obtaining support and enthusiasm for participation is expected to become more challenging as malaria transmission becomes lower [2,11,12]. However, the lack of perceived risk of disease and inadequate knowledge about the reasons for conducting interventions are the two most influential factors negatively affecting acceptability of communicable disease control and elimination programmes [2]. Therefore, it is vital to promote community understanding of the whole picture of malaria control interventions conducted in the community, especially about the role that community members play in the full system and how their actions and efforts might lead to a decrease in local malaria incidence. In this study, sign digraphs were developed using a method of qualitative modelling, loop analysis, to demonstrate how community-based malaria control could work in complex systems.

\section{Methods}

\section{Loop analysis to develop sign digraphs}

Details of the procedure to conduct loop analysis have been described elsewhere [10,13-15], and the method has been utilized as a standard approach mainly in ecology and biology [16-20]. Briefly, loop analysis consists of the analysis of sign digraphs, which show whether increases in one variable qualitatively increases or decreases other variables, or leaves them unchanged. It does not require precise quantitative interaction rates for the system being studied. The directions of associations between variables can be shown as a community matrix, which is a set of signs of interaction rates for each pair of variables [21]. The following matrix is an example of two variables, $\mathrm{x}_{1}$ and $\mathrm{x}_{2}$. The effect from a variable $\mathrm{x}_{2}$ on $\mathrm{x}_{1}\left(\mathrm{a}_{12}\right)$ is negative $(-)$, whereas that of variable $\mathrm{x}_{1}$ on $\mathrm{x}_{2}\left(\mathrm{a}_{21}\right)$ is positive $(+)$. The variable $\mathrm{x}_{2}$ also has a negative effect on itself when excessive levels are reached, which is called self-damping $\left(\mathrm{a}_{22}\right)$. Here, positive or negative entries $(+1$ or -1$)$ do not mean that the magnitude of the interactions between variables is equal.

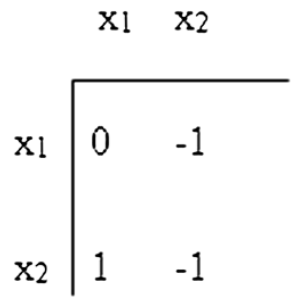

The above matrix corresponds to a sign digraph, using symbols of loop analysis, as shown below.

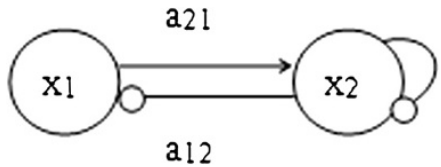

An arrow from one variable to another denotes that the variable has a positive effect on the other, while a line ending in a circle denotes a negative effect on the other variable or itself. Here, the arrow $a_{21}$ from $x_{1}$ to $x_{2}$ indicates a positive effect, and the line ending in a circle $\left(\mathrm{a}_{12}\right)$ from $\mathrm{x}_{2}$ to $\mathrm{x}_{1}$ indicates a negative effect. Variable $\mathrm{x}_{2}$ is self-damped, represented by a line ending in a circle at itself $\left(\mathrm{a}_{22}\right)$. (In Figures 1, 2, 3, 4, 5, 6 and 7, a comma is inserted between two numbers of variables for clarity.)

\section{Steps taken to develop sign digraphs for this study}

First, out of the interventions described in the World Malaria Report 2012 [1], seven major interventions, which are currently conducted at community level and involve community residents and/or community health workers, were selected. They include source reduction, insecticide/larvicide use (including indoor residual spraying (IRS), biological control, treatment with anti-malarials, ITN/LLIN, non-chemical personal protection measures, and educational intervention. Pathways through which each intervention could change local malaria incidence were identified. A sign digraph was then created for each 


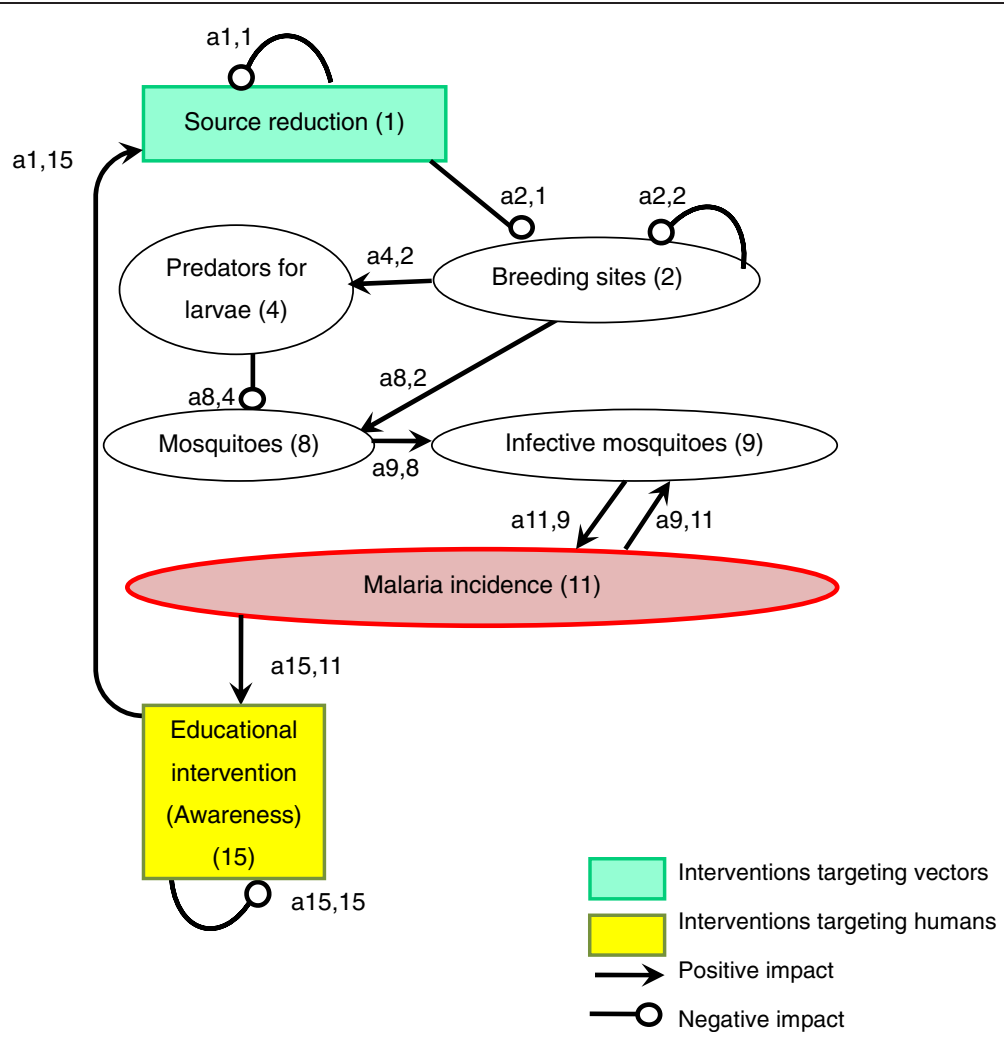

Figure 1 Source reduction.

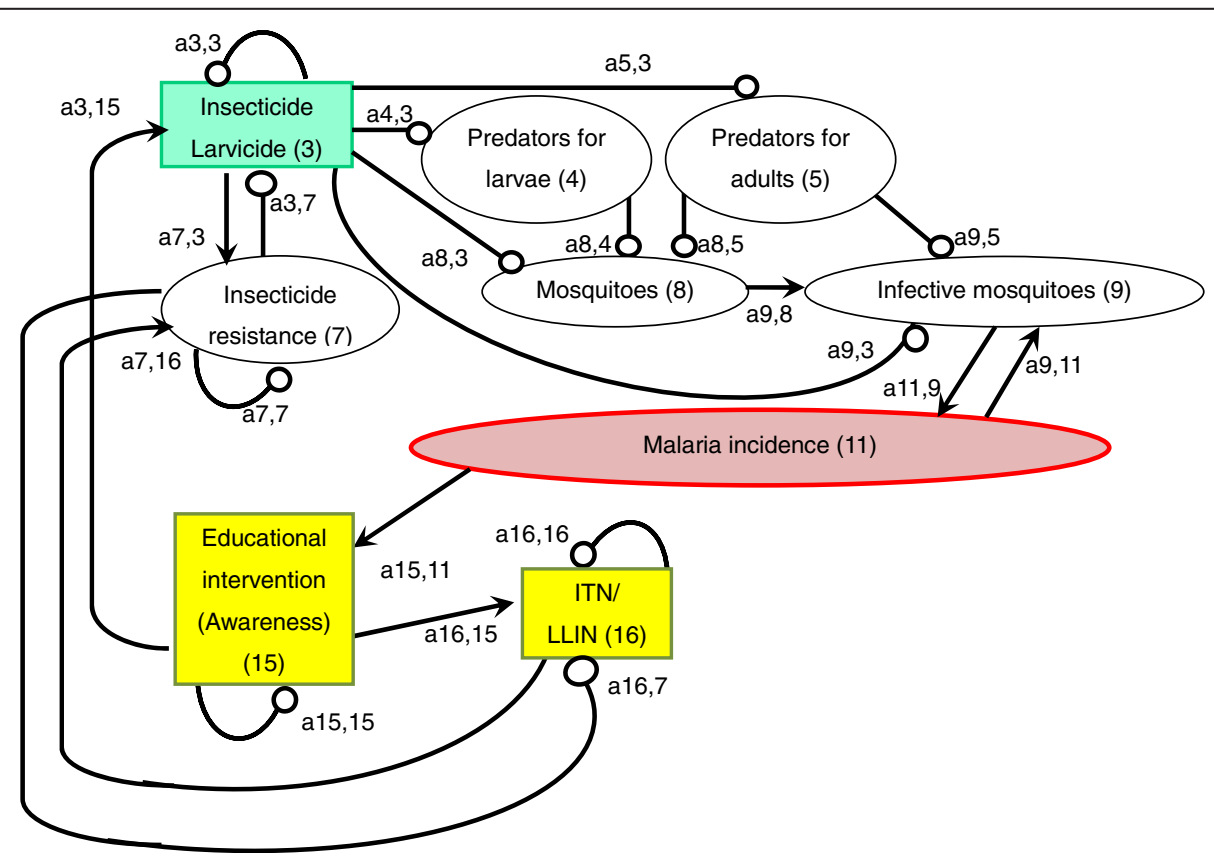

Figure 2 Insecticide and larvicide use. 


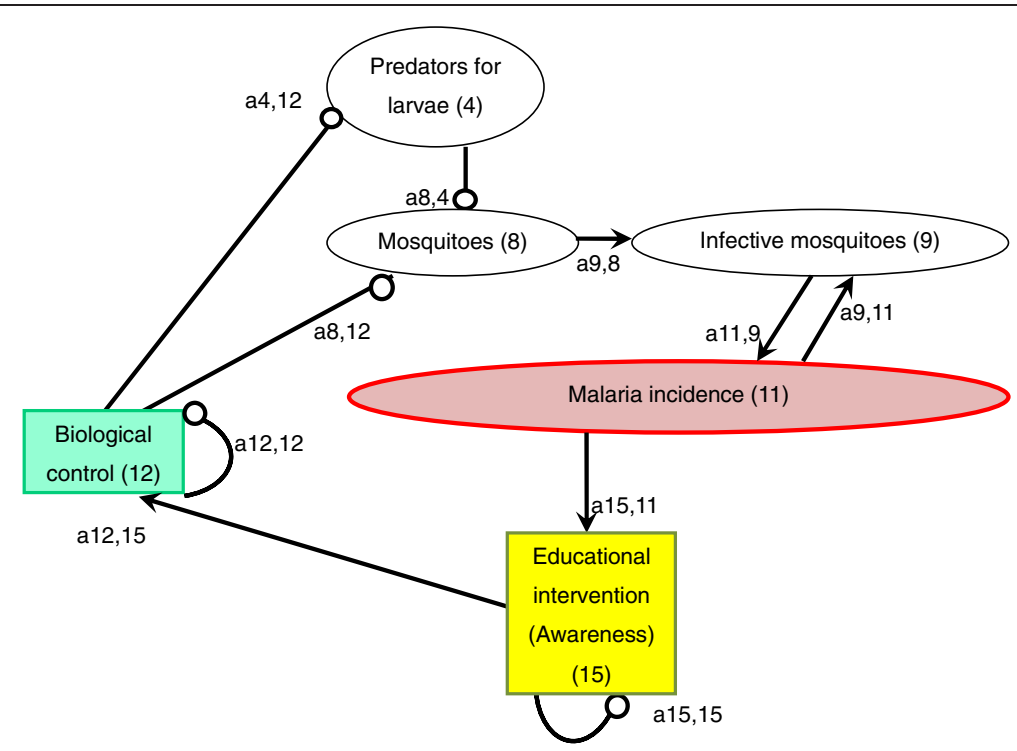

Figure 3 Biological control.

intervention with the loop analysis method, connecting variables involved in the pathways. If any of the other six interventions were relevant to the intervention, they were included in the same sign digraph. (For example, all sign digraphs include the variable "educational intervention" because it has a positive impact on other interventions.) Each variable was randomly numbered so each pathway can be described in the text simply using the numbers. (For example, a negative impact of a variable "Source reduction (1)" on another variable "Breeding sites (2)" is described as " $\mathrm{a}_{21}(-)$ " in text). The decision on which sign to be used (positive, negative, or null) for each connection between variables was made based on a literature review of each intervention. Developing sign digraphs by combining the method of loop analysis and literature review is a unique approach taken in this study to qualitatively assess the mechanisms of how community-based malaria control intervention could influence local malaria incidence. Unlike other approaches to map out interventions, such as the intervention mapping approach [22], loop analysis examines the interactions between variables involved in the interventions of interest.

\section{Literature search}

Peer-reviewed scientific literature on community-based malaria control interventions was searched through Pubmed/MEDLINE using keywords "malaria" and "community" as major subjects. To search the literature for each intervention, these keywords were combined with terms referring to different types of interventions and

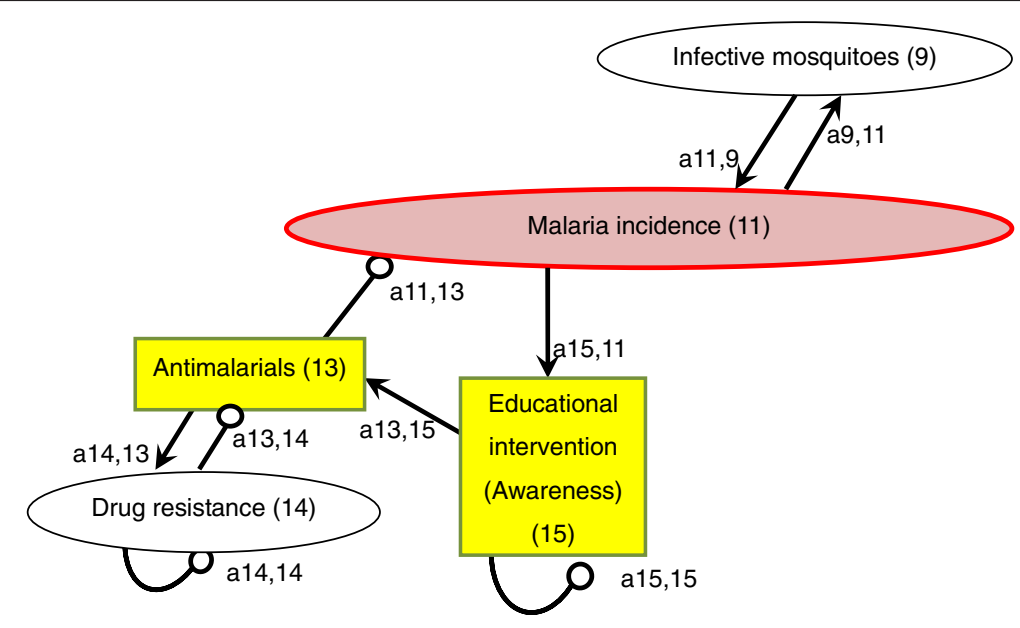

Figure 4 Anti-malarials. 


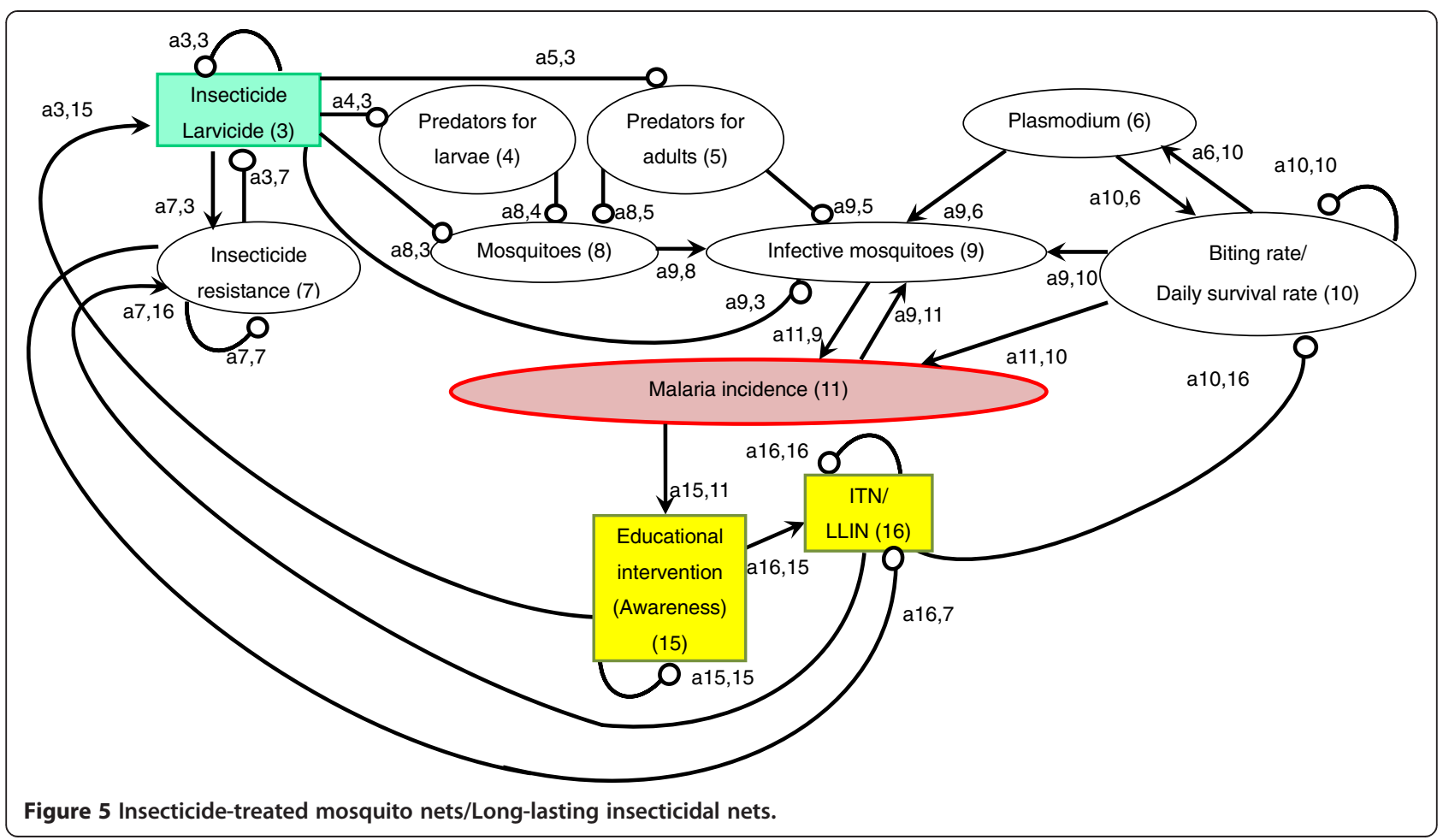

related variables, including "source reduction", "insecticide", "insecticide residual spraying", "larvicide", "biological control", "mosquito fish", "anti-malarials", "education", "awareness", "bed net", "insecticide-treated net", "personal protection", "house", and "resistance". Reference lists in the literature found were reviewed for additional articles. Then, relevant articles that explain the associations between variables in the sign digraphs were selected. Although information or data from primary sources were preferred, more general reviews and texts were also consulted.

\section{Results}

\section{Source reduction}

Source reduction provides the dual benefits of reducing the number of both indoor- and outdoor-biting mosquitoes

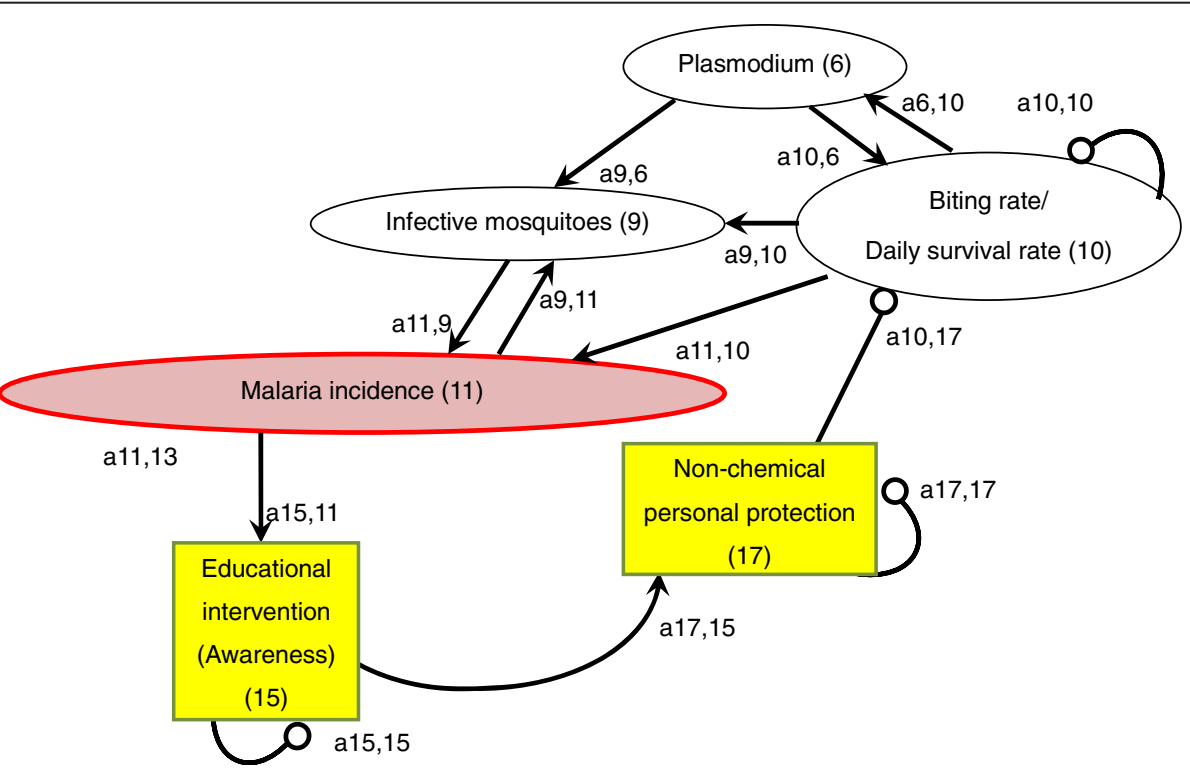

Figure 6 Non-chemical personal protection measures. 


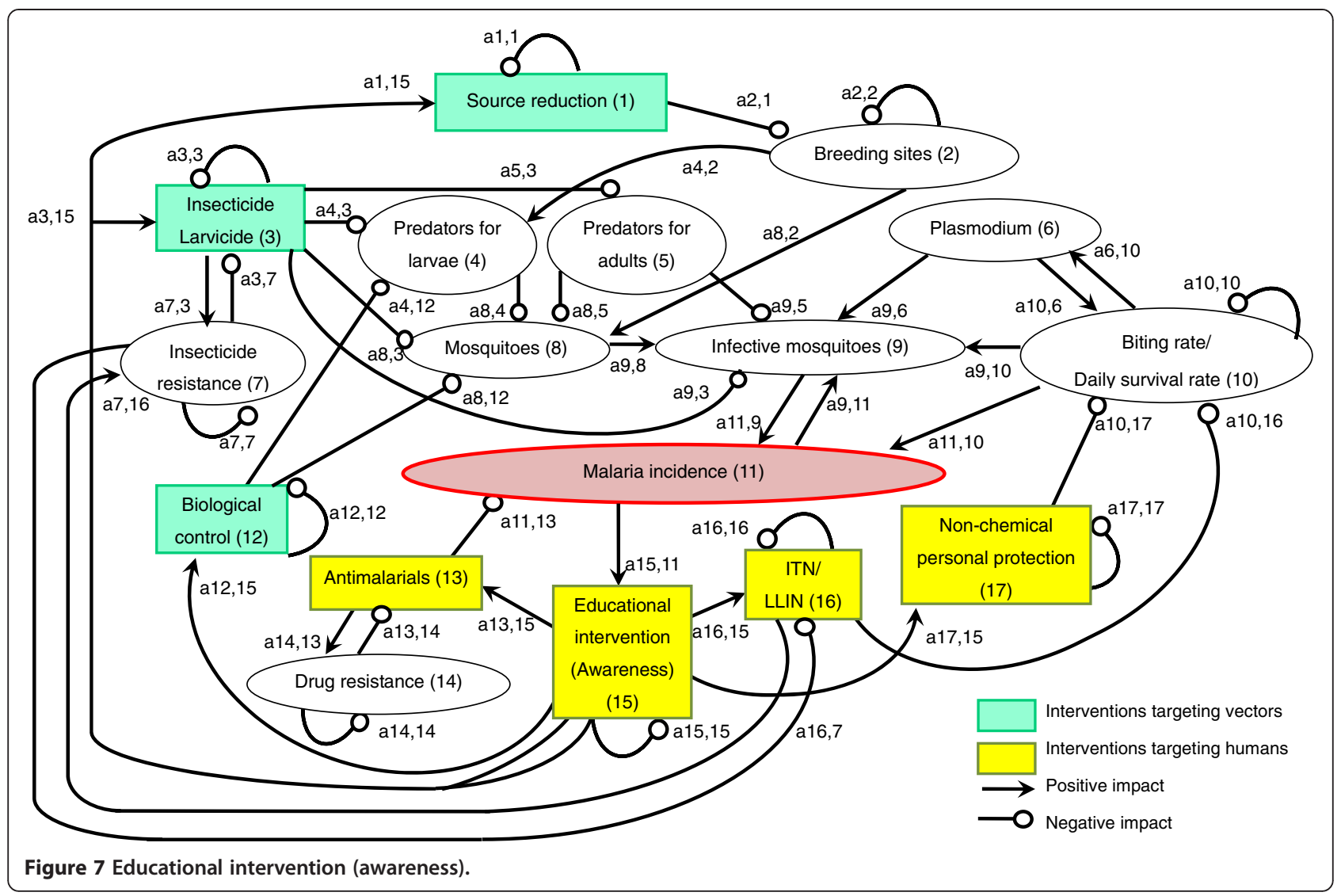

[23] (Figure 1). In the sign digraph, the impact of source reduction on infective mosquitoes is shown by three lines: first, a negative line from "Source reduction (1)" to "Breeding sites (2)"; second, a positive arrow from "Breeding sites (2)" to "Mosquitoes (8)"; and third, a positive arrow from "Mosquitoes (8)" to "Infective mosquitoes (9)". All over, the direction of the impact of source reduction on infective mosquitoes can be "negative times positive times positive = negative" [a2,1(-) x a8,2(+) x a9,8(+) = infective mosquitoes $(-)$ ] [24]. Source reduction activities include elimination of water-holding containers, filling standing water where mosquitoes oviposit and develop, field drainage, and cleaning and flushing of irrigation canals [5,25-27]. These activities can prevent mosquitoes from breeding simply by decreasing the number of aquatic habitats or the volume of standing water $[\mathrm{a} 2,1(-)]$. Altering the distribution of aquatic habitats is also an important aspect of source reduction because extended prolonged oviposition cycles, caused by increasing the amount of time required for mosquitoes to locate oviposition sites, can reduce the basic reproductive rate of malaria [28]. Furthermore, source reduction can aggregate mosquito larvae and their predators, such as aquatic insects, into a smaller number of breeding sites and encourage aquatic insects to prey on mosquito larvae [a8,4 $(-)$ [ [5]. Source reduction could indeed have played an important role in eradicating malaria from Israel, the USA and Italy [23,27] and in some local elimination programmes in Africa [26,29] by taking the following pathway $[\mathrm{a} 2,1(-)$ x $\mathrm{a} 8,2(+) \quad \mathrm{x}$ a9,8(+) $\mathrm{x}$ a11,9(+) = malaria incidence $(-)]$. Because the abundance and distribution of aquatic habitats are important determinants for local malaria transmission intensity and risk, source reduction can be more effective than applying larvicide [27].

While LLINs and IRS target mainly indoor-biting mosquitoes, source reduction can reduce both indoorand outdoor-biting mosquitoes [24]. Because outdoor biting is becoming a more important feature of malaria transmission [30,31], the importance of source reduction is revisited, as this is one of the few effective strategies to reduce outdoor-biting mosquitoes [24]. However, decreasing availability of breeding sites can also reduce proliferation of predators of larvae $[\mathrm{a} 2,1(-) \times \mathrm{a} 4,2(+) \times \mathrm{a} 8,4(-)=$ mosquitoes $(+)]$. Therefore, this negative impact on mosquito predators needs to be taken into consideration when forecasting the overall impact of source reduction on the increase in infective mosquitoes.

The impact of educational intervention in promoting source reduction and other interventions is compiled in the final subsection of Results. 


\section{Insecticide and larvicide use}

\section{Insecticide use for adult mosquitoes (IRS)}

Of the three major malaria control strategies (IRS, LLIN and prompt and effective treatment) promoted by the Roll Back Malaria Partnership (RBM) [32], two rely on chemicals (Figure 2). In order to directly suppress the abundance of adult mosquitoes by IRS, WHO approves the use of 12 insecticides of four chemical classes (organochlorines, organophosphates, carbamates, and pyrethroids) [33,34]. Several countries recently added IRS to their national malaria control plans in line with $\mathrm{RBM}$ [35], and 79 malaria-endemic countries reported the use of IRS for malaria prevention [1]. As a result, IRS has significantly reduced malaria vectors and malaria incidence $[a 9,3(-)$ x a11,9(+) = malaria incidence(-)] [36-40].

Two major challenges that chemical use has been facing in terms of reducing malaria incidence are disturbances to the natural balance, such as predator-prey relationships and mosquitoes' insecticide resistance. Chemical insecticides and pesticides not only reduce the abundance of target organisms but also that of beneficial organisms, such as predators, either directly by toxicity or by eliminating their prey organisms $[41,42]$. Chemical use for malaria vector control can result in reduced abundance of predators, especially in aquatic larval habitats, and a subsequent increase in vector mosquitoes $[\mathrm{a} 5,3(-) \mathrm{x}$ a8,5(-) $\mathrm{x}$ a9,8(+) = infective mosquitoes $(+)][41,43,44]$.

The other major challenge is mosquitoes' resistance to chemicals. Because chemical insecticide interventions have been scaled up during the past decade, mosquitoes' resistance has been spreading worldwide [1,3,45]. In 2012, 64 countries reported resistance to at least one insecticide in one malaria vector in one study site, and most of the resistance was against pyrethroids [1]. Due to the heavy reliance on one class of insecticides, the pyrethroids, mosquitoes' resistance to pyrethroids has been spreading at an exceptionally rapid rate, especially in Africa $[1,46]$. As a result, resistance began to threaten the sustainability of insecticide-based malaria control interventions $[\mathrm{a} 7,3(+) \times \mathrm{a} 3,7(-) \times \mathrm{a} 9,3(-) \times \mathrm{a} 11,9(+)=$ malaria incidence $(+)][3,4,47,48]$. At the same time, there is a possibility that mosquito predators have developed or will develop insecticide resistance, which favours predator population and might suppress mosquito proliferation $[\mathrm{a} 7,3(+) \times \mathrm{a} 3,7(-) \times \mathrm{a} 5,3(-) \times \mathrm{a} 8,5$ $(-)=$ mosquitoes $(-)]$.

There is an urgent need to develop new vector control interventions. This is because the above-stated challenges exist and also because many of the anopheline species are not susceptible to current insecticide-based interventions such as IRS and LLINs, which target indoor-feeding/resting vectors $[3,49]$. New vector control interventions need to be developed and implemented, taking mosquito ecology into consideration, such as site preferences for feeding, resting (especially outdoor), and oviposition, mating behaviour, and sugar meal selection [3].

\section{Larvicide use}

One of the most common interventions conducted to control mosquito larvae is the application of larvicide such as Bacillus thuringiensis israelensis (Bti) and Bacillus sphaericus (Bs) [24]. Several previous studies reported the effectiveness of larvicides in controlling malaria transmission. For example, hand-applied larviciding reduced transmission by $70-90 \%$ in Africa where the majority of aquatic mosquito larval habitats were defined and the aquatic surface was not too extensive [a8,3(-) $\mathrm{x}$ a9,8(+) $\mathrm{x}$ a11,9(+) = malaria incidence $(-)][24,50-52]$.

The application of larvicide for larval control can be effective in reducing not only the abundance of indoorbiting/resting mosquitoes, which IRS and LLINs target, but also of outdoor-biting/resting mosquitoes. However, several limitations have been reported. They include disturbance to local ecosystems such as predator-prey relationships [a $4,3(-) \times$ a8,4(-) = mosquitoes $(+)][41,53]$, mosquitoes' resistance to larvicides $[\mathrm{a} 7,3(+) \mathrm{x}$ a3,7(-) $\mathrm{x}$ a8,3(-) $=$ mosquitoes $(+)$ ] [54-56] and ineffectiveness in extensive water bodies [24,57]. In addition, Bti lacked inherent residual activity outside of potable container habitats, especially in habitats with turbid water or high organic loading [58].

\section{Biological control}

Interest in formulating non-chemical approaches has been growing over the past four decades because of the limitations of chemical use, including mosquitoes' insecticide resistance, disturbances to the ecosystem, and the health risks for human and domestic animals [5,59]. Current biological control tools that are considered most promising for malaria prevention include fungi, bacteria, larvivorous fish, parasites, viruses, and nematodes [60] (Figure 3). Among these, one of the most commonly used biological control agents is larvivorous fish, which are introduced to aquatic habitats of mosquitoes. Not only naturally occurring predators [61-64] but also introduced predators [24] can be effective in suppressing anopheline larval population.

Larvivorous fish, especially Gambusia (Gambusia affinis) and Guppy (Poecilia reticulata), are the most widely disseminated biological control agent in the world. Many of the introductions were made to control anopheline species that transmit malaria [65]. The usefulness of $G$. affinis in malaria control programmes was reported as early as the beginning of the 1900s in Europe, noting that the fish had a definite impact on the suppression of the disease $[\mathrm{a} 8,12(-) \times \mathrm{a} 9,8(+) \times \mathrm{a} 11,9(+)=$ malaria incidence(-)]. Later in 1970, an extensive release programme was carried out in Iran, which demonstrated the important roles of $G$. 
affinis in malaria eradication [66]. The introduction of these larvivorous fish has been reported to be effective in controlling local malaria by recent studies as well, especially in Asia and Africa [67-69].

A major objection to the introduction of larvivorous fish has been their direct impact on native fish species through predation or their indirect impact through competition $[\mathrm{a} 4,12(-)]$. So far, more than 30 species of native fish and other aquatic invertebrates co-inhabiting the same waters have been adversely affected by the introduction of $G$. affinis [66]. Also, the introduction of $G$. affinis did not show good results in pits, riverbed pools, stone quarries, ponds, drains, rice fields, and irrigation drains alongside rice fields [70]. In addition, G. affinis have been reported to be little more effective or equal or less effective in mosquito control compared to native fish species they replace. In California, native Cyprinodon macularius had an equal effectiveness in mosquito control [71]. Application of other biological agents also involve limitations, which vary depending on the agent [60]. Although their effectiveness is promising, the use of these biological means needs to be planned carefully, taking their impact on the local ecosystem into consideration.

\section{Anti-malarials}

Current malaria control measures directly targeting human beings rely heavily on a limited number of tools, particularly anti-malarial drugs (Figure 4) and LLINs, both of which have become less effective because of resistance. It was reported in 2011 that 79 countries/territories used artemisinin-based combination therapy (ACT) as first-line treatment for Plasmodium falciparum malaria $[a 11,13(-)=$ malaria incidence(-)]. For Plasmodium vivax malaria, it is recommended that chloroquine (combined with a 14-day course of primaquine) be used where it is effective, or an appropriate ACT in areas with chloroquine resistance [1].

Malaria treatment with ACT has been spreading over the world, but access to ACT at community level still needs to be improved. The number of ACT treatment courses delivered by manufacturers to the public and private sectors increased from 11 million in 2005 to 278 million in 2011. Surveys conducted in 12 African countries in 2010-2011 showed that about two thirds (median, 65\%) of all febrile children treated with an anti-malarial received an ACT. A greater proportion of children received ACT at health facilities not in the community. Therefore, expanding appropriate malaria treatment to the community level is urgently needed [1].

In addition to insufficient access to appropriate treatment, resistance to artemisinin derivatives has been posing a serious threat to malaria treatment $[\mathrm{a} 14,13(+) \mathrm{x}$ a13,14(-) $\mathrm{x}$ a11,13(-) = malaria incidence(+)]. Parasites' resistance to anti-malarial drugs arose from the extensive use and misuse of the drugs, particularly during the Global Malaria Eradication campaign, launched by WHO in 1955 [72]. So far, resistance of $P$. falciparum to artemisinin has been detected in Burma, Cambodia, China, Thailand, and Vietnam, [1,73-76]. Artemisinin resistance is a major threat to public health worldwide, especially to sub-Saharan Africa with the highest disease burden and inadequate systems for monitoring and containment of resistance [74].

One of the leading causes for the development of drug resistance is the spread of poor-quality anti-malarial drugs. It is very likely that widespread availability of counterfeit anti-malarials has been accelerating drug resistance in forested areas near the Thai-Cambodian border $[77,78]$. A recent review study found that up to $36 \%$ of anti-malarial drugs collected in Southeast Asia were falsified, and a third of anti-malarials collected in sub-Saharan Africa failed chemical assay analysis [79].

Intermittent preventive treatment (IPT) is also considered a cause of spreading resistance. IPT is a method proposed to reduce malaria morbidity and mortality by providing regularly spaced therapeutic doses of antimalarials to individuals, regardless of their malaria infection status [80]. IPT has been shown to be effective in reducing clinical malaria cases in pregnant women, children and infants [81-84]. For example, it was shown that IPT targeting preschool children (age $<$ six years) during the malaria transmission season markedly reduced clinical malaria cases, which occurred even in areas with high ITN use [81]. Despite its effectiveness, several studies suggested that IPT could accelerate the spread of resistance [85-87]. For example, IPT targeting infants is thought to accelerate the spread of resistant parasites in areas of low or unstable transmission and is more likely to accelerate the spread of resistance in high transmission areas than is IPT in adults [80].

To halt the spread of resistance, multiple strategies need to be employed. For example, it is crucial to improve facilities to check the quality of anti-malarial drugs and to strengthen drug-resistance surveillance and response systems. In western Cambodia (Pailin province), because resistance was found to both components of multiple ACT, special provisions for directly observed therapy using a non-artemisinin-based combination (atovaquone-proguanil) have been put in place [1]. Also, there is an urgent need for new antimalarial drugs that can kill gametocytes, not the asexual blood stage of the parasite, to prevent malaria transmission [88]. In addition to improving diagnosis and access to inexpensive genuine medicines, raising consumer and health-worker awareness and knowledge about counterfeit drugs and the consequences of their use is urgently needed at the community level $[74,79,89]$. 
Insecticide-treated bed nets/long-lasting insecticidal nets ITNs, including LLINs, are considered to be the most prominent malaria preventive measure, especially in highly malaria-endemic areas [36,46,90,91] (Figure 5). To achieve Millennium Development Goal 6, which aims to reduce child mortality by 2015, ITNs are one of the most important measures to be taken [92]. ITNs provide personal protection as well as community protection by decreasing the biting rate and daily survival rate of malaria vector mosquitoes $[\mathrm{a} 10,16(-) \mathrm{x}$ a11,10(+) = malaria incidence $(-)]$ [93-95] . ITNs can indirectly reduce malaria incidence through decreasing the infective mosquito population by affecting their survival $[\mathrm{a} 10,16(-) \times \mathrm{a} 9,10(+) \times$ a11,9(+) = malaria incidence $(-)$ ]. Reduced biting rate and daily survival rate can also affect the uptake of Plasmodium to mosquitoes and prevent mosquitoes from becoming infective [a10,16(-) $\mathrm{x}$ a6,10(+) x a9,6(+)=infective mosquitoes(-)] [96]. ITNs have been shown to be effective in reducing mortality from malaria in previous studies and randomized controlled trials [90,97-99]. A previous systematic review reported that ITNs significantly reduce the incidence of malaria compared to no nets and untreated nets in areas with stable malaria as well as with unstable malaria [a10,16(-) x a11,10 $(+)=$ malaria incidence $(-)][90]$.

During the past decade, ITN coverage has increased substantially. By 2012, 117 countries, including 34 in Africa, had adopted the WHO recommendation to provide ITNs to all persons at risk of malaria. A total of 88 countries, including 39 in Africa, distribute ITNs free of charge [100]. Distribution of ITNs has increased exponentially from 2007, especially in sub-Saharan Africa with household ownership of at least one ITN becoming an estimated $54 \%$ by $2013[45,100]$.

However, the number of ITNs delivered in 2011 and 2012 was below the number of ITNs required to protect all populations at risk [1]. Although rapid increase in ITN coverage has occurred in some of the poorest countries in Africa, coverage remains low among populations at risk. Among 44 African countries, only four have achieved ITN ownership coverage of $80 \%$ or greater. Countries with large populations at risk of malaria, such as Nigeria, continue to have low coverage. Overall, ITN ownership coverage was $32.8 \%$, and ITN use in children under five was $26.6 \%$ among 44 African countries in 2008 [98]. In addition, the proportion of the population sleeping under an ITN has been reported to be higher in wealthier, urban areas and lower among older children $[1,101,102]$. ITNs provided through free mass campaigns can actually preferentially cover children from the poorest quintile homesteads [102], and disparities in ITN access are expected to diminish as programmes move towards universal coverage [1].

Inappropriate use of ITNs is another serious issue related to malaria prevention. Household surveys conducted in
Africa from 2003-2011 indicated that approximately 90\% of the population with access to an ITN within the household actually used it. However, the population that used available nets included households in which nets were used beyond their assumed capacity as well as those in which nets were not used to full capacity [1]. ITN misuse has been increasingly reported. For example, ITNs are used as sleeping mats, for fishing or for drying fish, to protect crops and plants, as wedding veils, and as chicken coops [103-105]. Although a question remains as to whether the ITN misuse impedes ongoing malaria control efforts [103,104], further work is needed to ensure that all available nets are fully and properly utilized [1].

Resistance to pyrethroids, used for treating bed nets, is threatening the effectiveness of ITN use in reducing malaria incidence $[\mathrm{a} 7,16(+) \mathrm{x}$ a16,7(-) $\mathrm{x}$ a10,16(-) $\mathrm{x}$ a11,10(+) = malaria incidence $(+)],[a 7,16(+) \mathrm{x}$ a16,7(-) $\mathrm{x}$ a10,16(-) x a9,10 (+) x a11,9(+) = malaria incidence $(+)]$, and $[\mathrm{a} 7,16(+) \mathrm{x}$ a16,7(-) $\mathrm{x}$ a10,16(-) $\mathrm{x}$ a6,10 (+) $\mathrm{x}$ a9,6(+) $\mathrm{x}$ a11,9(+) = malaria incidence $(+)][46,48,91,106]$. For the treatment of bed nets, only six insecticides, all of which belong to the pyrethroid class, are allowed by WHO (WHO Pesticide Evaluation Scheme). The use of pyrethroids in malaria vector control has increased dramatically in the past decade through the scale up of ITN distribution programmes and IRS campaigns in Africa [46]. In addition, pyrethroids are widely used to control agricultural pests, which can pose additional selection pressure on mosquitoes when insecticides contaminate larval habitats. This intensive exposure to insecticides has inevitably resulted in the evolution of insecticide resistance in anopheline mosquitoes [34], and the resistance alleles have been spreading at an exceptionally rapid rate throughout Africa [46].

In spite of the rapid spreading of pyrethroid resistance, few studies have examined the impact of ITN use on malaria control. Controversy remains about the epidemiological significance of current levels of resistance in sub-Saharan Africa [46]. A recent study conducted in Benin demonstrated that resistance seriously threatens ITN-based malaria control interventions because ITNs provide little or no protection once vectors became resistant and netting acquires holes [106]. However, another study in seven locations in Africa reported that ITNs were cost effective for malaria control even in areas with strong pyrethroid resistance [91].

\section{Non-chemical personal protection measures}

Personal protection measures against mosquito-borne diseases with non-chemical approaches are considered to be potentially important [107] (Figure 6). Such measures include wearing light-coloured clothing, long trousers, long-sleeved shirts, and avoiding areas with high mosquito density. The effectiveness of such measures in 
reducing malaria incidence has not been well examined and needs to be studied. However, the improvement of house design has already been proven to be effective as a personal protection measure that does not rely on chemicals.

Improving the domestic environment, such as house design and screening, can be a non-chemical, complementary approach to increasing personal protection against indoorbiting malaria vectors and interrupting the malaria transmission cycle $[\mathrm{a} 10,17(-) \mathrm{x}$ a11,10(+) = malaria incidence $(-)]$ [108-111]. Transmission of malaria and other mosquitoborne diseases can be facilitated by poor house design that favours mosquito entry [112-114]. For example, the lack of window/door screening, presence of eave gaps and lack of a ceiling have been reported to enhance mosquitoes' entry into houses [109,115-118].

It has been demonstrated that the improvement of house design significantly contributes to the reduction in mosquito density inside houses and to the control and reduction of malaria vectors $[\mathrm{a} 10,17(-) \times$ a9, $10(+)=$ infective mosquitoes $(-)]$. The method includes screening (even with used bed nets or untreated shade cloth for agricultural use) [109,119-122], blocking all potential house entry points for mosquitoes [116,117] and building houses on stilts [123].

\section{Educational intervention (awareness)}

Community participation is vital for successful malaria control [2,124-127]. A recent review study identified the three most influential factors for community participation: knowledge and perception of disease, multisectoral collaboration and integration of programme(s) into broader development goals, and decentralization of power and resources and the use of community assets [2]. In order to raise community awareness and to involve the community in malaria control interventions, a variety of educational programmes have been conducted in malaria-prone countries (Figure 7).

The effectiveness of such community-based educational programmes in promoting malaria control with community participation has been reported by several studies. For example, a study from Nigeria demonstrated that it was health education, not free distribution, that significantly increased the use of ITNs among community residents [a16,15(+)] [128]. In Ethiopia, a cluster randomized trial demonstrated that the burden of malaria among children under five (examined by mass blood investigation) was significantly reduced by training household heads on the utilization of LLINs [a16,15(+) $\mathrm{x}$ a10,16 (-) x a11,10(+) = malaria incidence $(-)]$ [129].

Educational interventions targeting community residents and community health workers have improved community actions to promote early diagnosis and treatment of malaria $[a 13,15(+)]$. Recent studies from Nigeria indicated that a reduction in the incidence of malaria can be achieved by conducting training programmes for caregivers of children under five, which improved their knowledge, home management of malaria and referral practices for severe malaria $[\mathrm{a} 13,15(+) \mathrm{x}$ a11,13(-) $\mathrm{x}=$ malaria incidence(-)] $[130,131]$. Another study reported that a treatment guideline for the effective case management of malaria for children at home, developed by the joint efforts of researchers and community members, not only built capacity at the community level but also increased the acceptability and ownership of such materials [132]. In addition, training of community health workers has been reported to be effective in improving malaria diagnosis and treatment at the community level [a13,15(+)]. In Cambodia, community residents were trained as Village Malaria Workers and became effective in diagnosing malaria with rapid diagnostic tests (RDTs) and prescribing anti-malarials to malaria patients [133]. In Uganda, lay community health workers were trained and successfully diagnosed and treated malaria and pneumonia in children [134]. Training drug vendors, who can play a role in spreading information within a community, was also shown to be effective in improving prompt and appropriate treatment of malaria and referral of severe cases [135].

Source reduction was also promoted by community residents who were motivated and trained by different educational interventions [a1,15]. A community-based educational intervention, which was conducted for rice farmers in Sri Lanka, kept high participation rates and had a significant positive impact on the knowledge and varieties of actions farmers took for mosquito control and mosquito-borne disease prevention [136]. The farmers' environmental management activities, including source reduction, were demonstrated to be effective in reducing the density of adult female anophelines $[\mathrm{a} 1,15(+) \mathrm{x}$ a2,1(-) $\mathrm{x}$ a8,2(+) = mosquitoes(-)] [5].

Effective implementation of IRS and application of larvicide also need educational programmes to improve community understanding and acceptance by community residents $[a 3,15(+)]$. Previous studies reported that community residents' understanding of the function of the IRS, especially its effectiveness and unwanted sideeffects, was related to their compliance with the IRS programme [137-139]. One of the studies reported that the most frequent suggestion for improving community acceptance of IRS was to increase the understanding of the objectives of spraying in the communities [138].

Biological control of vectors and personal protection from malaria depends on community understanding, which educational intervention can improve. A previous study demonstrated that the successful implementation of biological control using fish, Toxorhynchites mosquitoes, Notonecta species, predatory copepods, 
entomopathogenic bacteria, and the fungus Lagenidium giganteum depended on the community's in-depth understanding of the ecology of these agents and targeted species [140]. Another study showed that an educational intervention increased community residents' activities to implement biological control using oil, salt and fish [a12,15(+)] [136]. Other previous studies have demonstrated the effectiveness of educational intervention in improving non-chemical personal protection measures taken by community residents and community health workers, such as wearing longsleeved shirts and long trousers and adding windows or door nets to houses [a17,15(+)] [136,141]. Several historical reports also describe that education was an essential part of mosquito control activities throughout the United States, especially in early $20^{\text {th }}$ century [142].

School education can also be an important strategy for community-based malaria control. A previous study in Ghana demonstrated that school-based participatory health education decreased malaria prevalence among school children and improved knowledge and practices of adults in the community [143]. However, a recent cross-country study reported that school textbooks of primary and lower secondary schools rarely covered knowledge and skills for malaria prevention and treatment [144]. Utilization of school education could further raise community awareness and encourage school children, their parents, and other community members to take additional actions for malaria control.

\section{Discussion}

This is the first study that has demonstrated how the impact of community-based malaria control interventions on malaria incidence can be examined by qualitative analysis, specifically loop analysis, combined with an extensive review of the literature that analyses each pathway. The sign digraphs developed in this study give a more complete picture of the complex system that can be created by a variety of malaria control efforts at the community level. By carefully mapping out relevant variables in the system, the digraph explains interactions and correlations among the variables involved. The sign digraphs show a variety of possible pathways through which each intervention can influence local malaria incidence. Combining sign digraphs of plural interventions can demonstrate changes in the variety and number of pathways as well as interactions between interventions.

Sign digraphs can demonstrate where uncertainties might exist in the complex system and what kinds of research are necessary to better understand how community-based malaria control interventions might influence local malaria incidence. For example, the sign digraph of source reduction (Figure 1), shows a negative impact of the reduction in mosquito breeding sites on mosquitoes' predators, which might eventually increase mosquito larval density in the long run $[\mathrm{a} 2,1(-) \quad \mathrm{x}$ a4,2(+) $\mathrm{x}$ a8,4(-)= mosquitoes $(+)]$. However, most previous studies focused only on source reduction's direct, short-term impact on mosquito larvae, and few studies have examined its impact on the ecology and density of predators. The diagram suggests that both pathways $([\mathrm{a} 2,1(-) \mathrm{x}$ a8,2(+) = mosquitoes $(-)]$ and $[\mathrm{a} 2,1(-) \mathrm{x}$ $\mathrm{a} 4,2(+) \mathrm{x}$ a8,4(-) $=$ mosquitoes $(+)])$ need to be studied in order to accurately evaluate the overall impact of source reduction on larval mosquitoes.

A sign digraph can also be useful to qualitatively examine the mechanisms of how combined effects of plural interventions can be generated. Recent studies have demonstrated that the combination of IRS and ITN use resulted in greater reductions in malaria incidence compared to the use of IRS or ITNs alone $[36,145,146]$. However, the sign digraph (Figure 2) shows that insecticide use is interlinked with ITN use through insecticide resistance and that the combined use of these measures can each diminish the effectiveness of the other by further accelerating the spread of resistance. Although some studies have suggested that the insecticides used for IRS and ITNs in the same region should belong to different classes to prevent the development and spread of insecticide resistance $[36,146]$, few studies have monitored how insecticide resistance progresses with the combination of the two interventions compared to the use of one of them. This way, a sign digraph demonstrates benefits and drawbacks of combining plural interventions as well as the need of further research on issues that have not been well examined.

Several vital issues for the effective implementation of each intervention, including sustainability and costbenefit analysis, need to be considered when interpreting a sign digraph. For example, although a sign digraph explains pathways through which community awareness and educational interventions can influence local malaria incidence (Figure 7), it does not show how long the impact of the educational intervention or raised awareness could last. The literature search revealed few studies that evaluated the long-term impact of educational interventions on community awareness, actions and malaria incidence. Such research is urgently needed. A deeper understanding of the sustainability of community participation is vital to encourage communities to continue their malaria control activities even when malaria incidence decreases with remaining transmission occurring in defined foci $[147,148]$.

The costs and benefits of each intervention also need to be taken into consideration. In most cases, community awareness and cost-benefit analysis conducted by community members can vary over time. Whether or not a community-based malaria control intervention can be sustained depends on a variety of issues, especially the cost of different materials and activities necessary to 
conduct the intervention. Such cost can vary by season because it not only includes direct costs to purchase materials or tools but also community members' time taken from other activities such as agriculture and fishing. As local malaria incidence decreases, it becomes increasingly difficult to sustain community awareness and participation $[2,11,12]$ and to persuade governments to allocate funding to maintain effective interventions. Since 1930, 75 resurgences of malaria have been recorded, nearly all of which were linked to the scaling back of interventions [76,149]. Considering such variations over time when interpreting a sign digraph could strengthen understanding of the mechanisms of how each intervention might work to decrease local malaria incidence.

One of the limitations of the study is that, mainly due to the nature of qualitative analysis, magnitudes of the interactions between variables were not examined. Therefore, it was impossible to quantitatively compare the impact of different interventions on malaria incidence and to examine the combined effects of plural interventions on malaria incidence. Also, to examine the interaction between variables involved in the system, different kinds of literature had to be combined regardless of their methods of analysis. Some studies conducted quantitative analysis while others only provided descriptive information without statistics showing the extent of changes. Publication bias might have influenced this study's analysis to some extent because most of the articles have dealt with the positive or negative impact of one variable on another rather than null effects.

Despite these limitations, this is the first study to qualitatively review the impact of malaria control interventions on malaria incidence, using the loop analysis method. Without relying on numerical data, this study was able to describe pathways through which each intervention could influence malaria incidence on the basis of the qualitative patterns of the interactions among variables in complex systems. It contributed to a better understanding of the mechanisms of how each malaria control intervention could influence malaria incidence, examined the associations and correlations among a variety of factors involved, and explained how unexpected consequences may have occurred. This methodology can be utilized not only by researchers but also by community leaders, local health programme and project officers, and policy makers to better plan and conduct their community-based malaria control interventions. It is also applicable to future studies to review the impact of malaria and other disease control interventions at community, national, and global levels.

\section{Competing interests}

The authors declare that they have no competing interests.

\section{Authors' contributions}

JY conceived the study, conducted analysis and literature review, and wrote the manuscript. MJ contributed to the interpretation of the analysis and improved the manuscript. RL provided guidance to conduct analysis and improved the manuscript. All authors read and approved the final draft.

\section{Acknowledgements}

We are grateful to Dr Anne M Johnson for her helpful advice on the manuscript.

\section{Author details}

${ }^{1}$ Department of Community and Global Health, The University of Tokyo, 7-3-1 Hongo, Bunkyo-ku, Tokyo 113-0033, Japan. ${ }^{2}$ Department of Global Health and Population, Harvard School of Public Health, 665 Huntington Avenue, Boston, MA 02115, USA

Received: 7 December 2013 Accepted: 1 April 2014

Published: 9 April 2014

\section{References}

1. WHO: World Malaria Report 2012. Geneva: World Health Organization; 2012.

2. Atkinson J-A, Vallely A, Fitzgerald L, Whittaker M, Tanner M: The architecture and effect of participation: a systematic review of community participation for communicable disease control and elimination. Implications for malaria elimination. Malar J 2011, 10:225.

3. malERA Consultative Group on Vector Control: A research agenda for malaria eradication: vector control. PLoS Med 2011, 8:e1000401.

4. Thomas MB, Godfray HC, Read AF, van den Berg H, Tabashnik BE, van Lenteren JC, Waage JK, Takken W: Lessons from agriculture for the sustainable management of malaria vectors. PLOS Med 2012, 9:e1001262

5. Yasuoka J, Levins R, Mangione TW, Spielman A: Community-based rice ecosystem management for suppressing vector anophelines in Sri Lanka. Trans R Soc Trop Med Hyg 2006, 100:995-1006.

6. Konradsen F, Amerasinghe FP, van der Hoek W, Amerasinghe PH: Malaria in Sri Lanka, Current Knowledge on Transmission and Control. Colombo: International Water Management Institute; 2000.

7. Silva KT: "Public health" for whose benefit? Multiple discourses on malaria in Sri Lanka. Med Anthropol 1997, 17:195-214.

8. Wiese M: Integrated approaches to malaria control - addressing new challenges to malaria research. Malar J 2012, 11:Poster 104.

9. Tanner M, de Savigny D: Malaria eradication back on the table. Bull World Health Organ 2008, 86:82

10. Levins R: Qualitative analysis of partially specified systems. Ann N Y Acad Sci 1974, 231:123-138.

11. Bauch JA, Gu JJ, Msellem M, Martensson A, Ali AS, Gosling R, Baltzell KA: Perception of malaria risk in a setting of reduced malaria transmission: a qualitative study in Zanzibar. Malar J 2013, 12:75.

12. Najera JA, Gonzalez-Silva M, Alonso PL: Some lessons for the future from the Global Malaria Eradication Programme (1955-1969). PLoS Med 2011 8:e1000412.

13. Levins R: Qualitative mathematics for understanding, prediction, and intervention in complex ecosystems. In Ecosystemhealth. Edited by Rapport D, Costanza R, Epstein PR, Gaudet C, Levins R. Malden: Blackwell Science, Inc; 1998:178-204.

14. Puccia CJ, Levins R: Qualitative modeling of complex systems: An introduction to loop analysis and time averaging. Cambridge: Harvard University Press; 1985

15. Justus J: Qualitative scientific modeling and loop analysis. Philos Sci 2005, 72:1272-1286

16. Dambacher JM, Ramos-Jiliberto R: Understanding and predicting effects of modified interactions through a qualitative analysis of community structure. Q Rev Biol 2007, 82:227-250.

17. Zavaleta JO, Rossignol PA: Community-level analysis of risk of vectorborne disease. Trans R Soc Trop Med Hyg 2004, 98:610-618.

18. Lane PA, Blouin AC: Plankton of an acid-stressed lake (Kejimkujik National Park, Nova Scotia, Canada). Part 3. Community network analysis. Verh Internat Verein Limnol 1984, 22:406-411.

19. Vandermeer J: Elementary Mathematical Ecology. New York: John Wiley and Sons, Inc.; 1981.

20. Boucher DH, James S, Keeler KH: The ecology of mutualism. Annu Rev Ecol Syst 1982, 13:315-347. 
21. Levins R: Evolution in changing environments: some theoretical explorations. Princeton, New Jersey, USA: Princeton University Press; 1968.

22. Bartholomew LK, Parcel GS, Kok G: Intervention mapping: a process for developing theory- and evidence-based health education programs. Health Educ Behav 1998, 25:545-563.

23. Kitron U, Spielman A: Suppression of transmission of malaria through source reduction: antianopheline measures applied in Israel, the United States, and Italy. Rev Infect Dis 1989, 11:391-406.

24. Fillinger $U$, Lindsay SW: Larval source management for malaria control in Africa: myths and reality. Malar J 2011, 10:353.

25. Dowling Z, Armbruster P, LaDeau SL, DeCotiis M, Mottley J, Leisnham PT: Linking mosquito infestation to resident socioeconomic status, knowledge, and source reduction practices in suburban Washington, DC. Ecohealth 2013, 10:36-47.

26. Yakob L, Yan G: Modeling the effects of integrating larval habitat source reduction and insecticide treated nets for malaria control. PLoS One 2009, 4:e6921.

27. Le Menach A, McKenzie FE, Flahault A, Smith DL: The unexpected importance of mosquito oviposition behaviour for malaria: non-productive larval habitats can be sources for malaria transmission. Malar J 2005, 4:23.

28. Gu W, Regens $J$, Beier JC, Novak RJ: Source reduction of mosquito larval habitats has unexpected consequences on malaria transmission. Proc Natl Acad Sci U S A 2006, 103:17560-17563.

29. Utzinger J, Tozan Y, Singer BH: Efficacy and cost-effectiveness of environmental management for malaria control. Trop Med Int Health 2001, 6:677-687.

30. Russell TL, Govella NJ, Azizi S, Drakeley CJ, Kachur SP, Killeen GF: Increased proportions of outdoor feeding among residual malaria vector populations following increased use of insecticide-treated nets in rural Tanzania. Malar J 2011, 10:80.

31. Reddy MR, Overgaard HJ, Abaga S, Reddy VP, Caccone A, Kiszewski AE, Slotman MA: Outdoor host seeking behaviour of Anopheles gambiae mosquitoes following initiation of malaria vector control on Bioko Island, Equatorial Guinea. Malar J 2011, 10:184.

32. Roll Back Malaria: The Global Malaria Action Plan. Geneva: Roll Back Malaria partnership; 2008

33. World Health Organization: WHO Pesticide Evaluation Scheme. http://www. who.int/whopes/en/

34. Ranson H, Abdallah H, Badolo A, Guelbeogo WM, Kerah-Hinzoumbe C, Yangalbe-Kalnone E, Sagnon N, Simard F, Coetzee M: Insecticide resistance in Anopheles gambiae: data from the first year of a multi-country study highlight the extent of the problem. Malar J 2009, 8:299.

35. Kigozi R, Baxi SM, Gasasira A, Sserwanga A, Kakeeto S, Nasr S, Rubahika D, Dissanayake G, Kamya MR, Filler S, Dorsey G: Indoor residual spraying of insecticide and malaria morbidity in a high transmission intensity area of Uganda. PLoS One 2012, 7:e42857.

36. Okumu FO, Moore SJ: Combining indoor residual spraying and insecticidetreated nets for malaria control in Africa: a review of possible outcomes and an outline of suggestions for the future. Malar J 2011, 10:208

37. Curtis CF, Mnzava AE: Comparison of house spraying and insecticide-treated nets for malaria control. Bull World Health Organ 2000, 78:1389-1400.

38. Kouznetsov RL: Malaria control by application of indoor spraying of residual insecticides in tropical Africa and its impact on community health. Trop Doct 1977, 7:81-91.

39. Mabaso ML, Sharp B, Lengeler C: Historical review of malarial control in southern African with emphasis on the use of indoor residual housespraying. Trop Med Int Health 2004, 9:846-856.

40. Pluess B, Tanser FC, Lengeler C, Sharp BL: Indoor residual spraying for preventing malaria. Cochrane Database Syst Rev 2010, 4:CD006657.

41. Service MW: Mortalities of the immature stages of species B of the Anopheles gambiae complex in Kenya: comparison between rice fields and temporary pools, identification of predators, and effects of insecticidal spraying. J Med Entomol 1977, 13:535-545

42. Muiruri SK, Mwangangi JM, Carlson J, Kabiru EW, Kokwaro E, Githure J, Mbogo CM, Beier JC: Effect of predation on Anopheles larvae by five sympatric insect families in coastal Kenya. J Vector Borne Dis 2013, 50:45-50.

43. Kweka EJ, Zhou G, Gilbreath TM 3rd, Afrane Y, Nyindo M, Githeko AK, Yan G: Predation efficiency of Anopheles gambiae larvae by aquatic predators in western Kenya highlands. Parasit Vectors 2011, 4:128.

44. Ohba SY, Kawada H, Dida GO, Juma D, Sonye G, Minakawa N, Takagi M: Predators of Anopheles gambiae sensu lato (Diptera: Culicidae) larvae in wetlands, western Kenya: confirmation by polymerase chain reaction method. J Med Entomol 2010, 47:783-787.
45. Coetzee M, Koekemoer LL: Molecular systematics and insecticide resistance in the major African malaria vector Anopheles funestus. Annu Rev Entomol 2013, 58:393-412.

46. Ranson H, N'Guessan R, Lines J, Moiroux N, Nkuni Z, Corbel V: Pyrethroid resistance in African anopheline mosquitoes: what are the implications for malaria control? Trends Parasitol 2011, 27:91-98.

47. Chanda E, Hemingway J, Kleinschmidt I, Rehman AM, Ramdeen V, Phiri FN, Coetzer S, Mthembu D, Shinondo CJ, Chizema-Kawesha E, Kamuliwo M, Mukonka V, Baboo KS, Coleman M: Insecticide resistance and the future of malaria control in Zambia. PLoS One 2011, 6:e24336.

48. Trape JF, Tall A, Diagne N, Ndiath O, Ly AB, Faye J, Dieye-Ba F, Roucher C, Bouganali C, Badiane A, Sarr FD, Mazenot C, Touré-Baldé A, Raoult D, Druilhe P, Mercereau-Puijalon O, Rogier C, Sokhna C: Malaria morbidity and pyrethroid resistance after the introduction of insecticide-treated bednets and artemisinin-based combination therapies: a longitudinal study. Lancet Infect Dis 2011, 11:925-932.

49. Terenius $O$, Marinotti $O$, Sieglaff D, James AA: Molecular genetic manipulation of vector mosquitoes. Cell Host Microbe 2008, 4:417-423.

50. Fillinger U, Kannady K, William G, Vanek MJ, Dongus S, Nyika D, Geissbuhler Y, Chaki PP, Govella NJ, Mathenge EM, Singer BH, Mshinda H, Lindsay SW, Tanner M, Mtasiwa D, de Castro MC, Killeen GF: A tool box for operational mosquito larval control: preliminary results and early lessons from the Urban Malaria Control Programme in Dar es Salaam, Tanzania. Malar J 2008, 7:20.

51. Fillinger $U$, Lindsay SW: Suppression of exposure to malaria vectors by an order of magnitude using microbial larvicides in rural Kenya. Trop Med Int Health 2006, 11:1629-1642.

52. Fillinger U, Ndenga B, Githeko A, Lindsay SW: Integrated malaria vector control with microbial larvicides and insecticide-treated nets in western Kenya: a controlled trial. Bull World Health Organ 2009, 87:655-665.

53. Miles AK, Lawler SP, Dritz D, Spring S: Effects of mosquito larvicide on mallard ducklings and prey. Wildl Soc Bull 2002, 30:675-682.

54. Soltani A, Vatandoost H, Oshaghi MA, Enayati AA, Raeisi A, Eshraghian MR, Soltan-Dallal MM, Hanafi-Bojd AA, Abai MR, Rafi F: Baseline susceptibility of different geographical strains of Anopheles stephensi (Diptera: Culicidae) to temephos in malarious areas of Iran. J Arthropod Borne Dis 2013, 7:56-65.

55. Paul A, Harrington LC, Zhang L, Scott JG: Insecticide resistance in Culex pipiens from New York. J Am Mosq Control Assoc 2005, 21:305-309.

56. Luong K, Dunkel FV, Coulibaly K, Beckage NE: Potential use of neem leaf slurry as a sustainable dry season management strategy to control the malaria vector Anopheles gambiae (Diptera: Culicidae) in west African villages. J Med Entomol 2012, 49:1361-1369.

57. Majambere S, Pinder M, Fillinger U, Ameh D, Conway DJ, Green C, Jeffries D, Jawara M, Milligan PJ, Hutchinson R, Lindsay SW: Is mosquito larval source management appropriate for reducing malaria in areas of extensive flooding in The Gambia? A cross-over intervention trial. Am J Trop Med Hyg 2010, 82:176-184.

58. Dritz DA, Lawler SP, Evkhanian C, Graham P, Baracosa V, Dula G: Control of mosquito larvae in seasonal wetlands on a wildlife refuge using VectoMax CG. J Am Mosa Control Assoc 2011, 27:398-403.

59. Lacey LA, Lacey CM: The medical importance of riceland mosquitoes and their control using alternatives to chemical insecticides. J Am Mosa Control Assoc Suppl 1990, 2:1-93.

60. Kamareddine $\mathrm{L}$ : The biological control of the malaria vector. Toxins (Basel) 2012, 9:748-767

61. Blaustein L, Chase JM: Interactions between mosquito larvae and species that share the same trophic level. Annu Rev Entomol 2007, 52:489-507.

62. Chandra G, Mandal SK, Ghosh AK, Das D, Banerjee SS, Chakraborty S: Biocontrol of larval mosquitoes by Acilius sulcatus (Coleoptera: Dytiscidae). BMC Infect Dis 2008, 8:138.

63. Carlson JC, Dyer LA, Omlin FX, Beier JC: Diversity cascades and malaria vectors. J Med Entomol 2009, 46:460-464.

64. Matias JR, Adrias AQ: The use of annual killifish in the biocontrol of the aquatic stages of mosquitoes in temporary bodies of fresh water; a potential new tool in vector control. Parasit Vectors 2010, 3:46.

65. Rupp HR: Adverse assessments of Gambusia affinis: an alternate view for mosquito control practitioners. J Am Mosq Control Assoc 1996, 12:155-159. discussion 160-156.

66. Legner EF: Adverse assessments of Gambusia affinis - Comments. J Am Mosa Control Assoc 1996, 12:161. 
67. Kant R, Haq S, Srivastava HC, Sharma VP: Review of the bioenvironmental methods for malaria control with special reference to the use of larvivorous fishes and composite fish culture in central Gujarat, India. J Vector Borne Dis 2013, 50:1-12.

68. Imbahale SS, Githeko A, Mukabana WR, Takken W: Integrated mosquito larval source management reduces larval numbers in two highland villages in western Kenya. BMC Public Health 2012, 12:362.

69. Kusumawathie PH, Wickremasinghe AR, Karunaweera ND, Wijeyaratne MJ: Costs and effectiveness of application of Poecilia reticulata (guppy) and temephos in anopheline mosquito control in river basins below the major dams of Sri Lanka. Trans R Soc Trop Med Hyg 2008, 102:705-711.

70. Sharma SN, Kaul SM, Lal S: Use of Gambusia affinis in different habitats as a mosquito control agent. J Commun Dis 1997, 29:371-373.

71. Walters LL, Legner EF: Impact of the desert pupfish, Cyprinodonmacularius, and Gambusia-affinis-affinis on fauna in pond ecosystems. Hilgardia 1980, 48:1-18.

72. D'Alessandro $\mathrm{U}$, Buttiens $\mathrm{H}$ : History and importance of antimalarial drug resistance. Trop Med Int Health 2001, 6:845-848.

73. Tulloch J, David B, Newman RD, Meek S: Artemisinin-resistant malaria in the Asia-Pacific region. Lancet 2013, 381:e16-17.

74. Talisuna AO, Karema C, Ogutu B, Juma E, Logedi J, Nyandigisi A, Mulenga M, Mbacham WF, Roper C, Guerin PJ, D'Alessandro U, Snow RW: Mitigating the threat of artemisinin resistance in Africa: improvement of drug-resistance surveillance and response systems. Lancet Infect Dis 2012, 12:888-896.

75. Amaratunga C, Sreng S, Suon S, Phelps ES, Stepniewska K, Lim P, Zhou C, Mao S, Anderson JM, Lindegardh N, Jiang H, Song J, Su XZ, White NJ, Dondorp AM, Anderson TJ, Fay MP, Mu J, Duong S, Fairhurst RM: Artemisinin-resistant Plasmodium falciparum in Pursat province, western Cambodia: a parasite clearance rate study. Lancet Infect Dis 2012, 12:851-858

76. Liu J, Modrek S, Gosling RD, Feachem RGA: Malaria eradication. Is it possible? Is it worth it? Should we do it? Lancet Global Health 2013, 1:1.

77. Dondorp AM, Newton PN, Mayxay M, Van Damme W, Smithuis FM, Yeung S, Petit A, Lynam AJ, Johnson A, Hien TT, McGready R, Farrar JJ, Looareesuwan S, Day NP, Green MD, White NJ: Fake antimalarials in Southeast Asia are a major impediment to malaria control: multinational cross-sectional survey on the prevalence of fake antimalarials. Trop Med Int Health 2004, 9:1241-1246.

78. Newton PN, Dondorp A, Green M, Mayxay M, White NJ: Counterfeit artesunate antimalarials in southeast Asia. Lancet 2003, 362:169.

79. Nayyar GM, Breman JG, Newton PN, Herrington J: Poor-quality antimalarial drugs in southeast Asia and sub-Saharan Africa. Lancet Infect Dis 2012, 12:488-496.

80. O'Meara WP, Smith DL, McKenzie FE: Potential impact of intermittent preventive treatment (IPT) on spread of drug-resistant malaria. PLoS Med 2006, 3:e141.

81. Meremikwu MM, Donegan S, Sinclair D, Esu E, Oringanje C: Intermittent preventive treatment for malaria in children living in areas with seasonal transmission. Cochrane Database Syst Rev 2012, 2, CD003756.

82. Bardají A, Bassat $\mathrm{Q}$, Alonso PL, Menéndez C: Intermittent preventive treatment of malaria in pregnant women and infants: making best use of the available evidence. Expert Opin Pharmacother 2012, 13:1719-1736.

83. Greenwood B, Bojang K, Tagbor H, Pagnoni F: Combining community case management and intermittent preventive treatment for malaria. Trends Parasitol 2011, 27:477-480.

84. Shulman CE, Dorman EK, Cutts F, Kawuondo K, Bulmer JN, Peshu N, Marsh K: Intermittent sulphadoxine-pyrimethamine to prevent severe anaemia secondary to malaria in pregnancy: a randomised placebocontrolled trial. Lancet 1999, 353:632-636.

85. Likwela JL, D'Alessandro U, Lokwa BL, Meuris S, Dramaix MW: Sulfadoxinepyrimethamine resistance and intermittent preventive treatment during pregnancy: a retrospective analysis of birth weight data in the Democratic Republic of Congo (DRC). Trop Med Int Health 2012, 17:322-329.

86. Sirima SB, Sawadogo R, Moran AC, Konate A, Diarra A, Yameogo M, Parise $M E$, Newman RD: Failure of a chloroquine chemoprophylaxis program to adequately prevent malaria during pregnancy in Koupela District, Burkina Faso. Clin Infect Dis 2003, 36:1374-1382.

87. Faye B, Ndiaye M, Ndiaye JL, Annie A, Tine RC, Lo AC, Sow D, De Sousa A, Gaye O: Prevalence of molecular markers of Plasmodium falciparum resistance to sulfadoxine-pyrimethamine during the intermittent preventive treatment in infants coupled with the expanded program immunization in Senegal. Parasitol Res 2011, 109:133-138.

88. Miller LH, Ackerman HC, Su XZ, Wellems TE: Malaria biology and disease pathogenesis: insights for new treatments. Nat Med 2013, 19:156-167.

89. Newton PN, Green MD, Fernandez FM, Day NP, White NJ: Counterfeit anti-infective drugs. Lancet Infect Dis 2006, 6:602-613.

90. Lengeler C: Insecticide-treated bed nets and curtains for preventing malaria. Cochrane Database Syst Rev 2004, 2:CD000363.

91. Briet OJ, Penny MA, Hardy D, Awolola TS, Van Bortel W, Corbel V, Dabire RK, Etang J, Koudou BG, Tungu PK, Chitnis N: Effects of pyrethroid resistance on the cost effectiveness of a mass distribution of long-lasting insecticidal nets: a modelling study. Malar J 2013, 12:77.

92. Noor AM, Mutheu JJ, Tatem AJ, Hay SI, Snow RW: Insecticide-treated net coverage in Africa: mapping progress in 2000-07. Lancet 2009, 373:58-67.

93. Hawley WA, Phillips-Howard PA, ter Kuile FO, Terlouw DJ, Vulule JM, Ombok M, Nahlen BL, Gimnig JE, Kariuki SK, Kolczak MS, Hightower AW: Community-wide effects of permethrin-treated bed nets on child mortality and malaria morbidity in western Kenya. Am J Trop Med Hyg 2003, 68:121-127.

94. Fink G, Masiye F: Assessing the impact of scaling-up bednet coverage through agricultural loan programmes: evidence from a cluster randomised controlled trial in Katete, Zambia. Trans R Soc Trop Med Hyg 2012, 106:660-667.

95. Eisele TP, Keating J, Littrell M, Larsen D, Macintyre K: Assessment of insecticide-treated bednet use among children and pregnant women across 15 countries using standardized national surveys. Am J Trop Med Hyg 2009, 80:209-214.

96. Koella JC, Sorensen FL, Anderson RA: The malaria parasite, Plasmodium falciparum, increases the frequency of multiple feeding of its mosquito vector, Anopheles gambiae. Proc Biol Sci 1998, 265:763-768.

97. Gamble C, Ekwaru JP, ter Kuile FO: Insecticide-treated nets for preventing malaria in pregnancy. Cochrane Database Syst Rev 2006, 2:Cd003755.

98. Flaxman AD, Fullman N, Otten MW Jr, Menon M, Cibulskis RE, Ng M, Murray CJ, Lim SS: Rapid scaling up of insecticide-treated bed net coverage in Africa and its relationship with development assistance for health: a systematic synthesis of supply, distribution, and household survey data. PLoS Med 2010, 7:e1000328.

99. White MT, Conteh L, Cibulskis R, Ghani AC: Costs and cost-effectiveness of malaria control interventions-a systematic review. Malar J 2011, 10:337.

100. WHO: World Malaria Report 2013. Geneva: World Health Organization; 2013.

101. Webster J, Lines J, Bruce J, Armstrong Schellenberg JR, Hanson K: Which delivery systems reach the poor? A review of equity of coverage of ever-treated nets, never-treated nets, and immunisation to reduce child mortality in Africa. Lancet Infect Dis 2005, 5:709-717.

102. Noor AM, Amin AA, Akhwale WS, Snow RW: Increasing coverage and decreasing inequity in insecticide-treated bed net use among rural Kenyan children. PLoS Med 2007, 4:e255.

103. Honjo K, Chaves LF, Satake A, Kaneko A, Minakawa N: When they don't bite, we smell money: understanding malaria bednet misuse. Parasitology 2013, 140:580-586.

104. Eisele TP, Thwing J, Keating J: Claims about the misuse of insecticide-treated mosquito nets: are these evidence-based? PLoS Med 2011, 8:e1001019.

105. Minakawa N, Dida GO, Sonye GO, Futami K, Kaneko S: Unforeseen misuses of bed nets in fishing villages along Lake Victoria. Malar J 2008, 7:165.

106. Asidi A, N'Guessan R, Akogbeto M, Curtis C, Rowland M: Loss of household protection from use of insecticide-treated nets against pyrethroidresistant mosquitoes, benin. Emerg Infect Dis 2012, 18:1101-1106.

107. van den Berg H: Global status of DDT and its alternatives for use in vector control to prevent disease. Environ Health Perspect 2009, 117:1656-1663.

108. Lwetoijera DW, Kiware SS, Mageni ZD, Dongus S, Harris C, Devine GJ, Majambere $S$ : A need for better housing to further reduce indoor malaria transmission in areas with high bed net coverage. Parasit Vectors 2013, 6:57.

109. Kirby MJ, Ameh D, Bottomley C, Green C, Jawara M, Milligan PJ, Snell PC, Conway DJ, Lindsay SW: Effect of two different house screening interventions on exposure to malaria vectors and on anaemia in children in The Gambia: a randomised controlled trial. Lancet 2009, 374:998-1009.

110. Baragatti M, Fournet F, Henry MC, Assi S, Ouedraogo H, Rogier C, Salem G: Social and environmental malaria risk factors in urban areas of Ouagadougou, Burkina Faso. Malar J 2009, 8:13.

111. Graves PM, Richards FO, Ngondi J, Emerson PM, Shargie EB, Endeshaw T, Ceccato P, Ejigsemahu Y, Mosher AW, Hailemariam A, Zerihun M, Teferi 
T, Ayele B, Mesele A, Yohannes G, Tilahun A, Gebre T: Individual, household and environmental risk factors for malaria infection in Amhara, Oromia and SNNP regions of Ethiopia. Trans R Soc Trop Med Hyg 2009, 103:1211-1220.

112. Kumar DV, Krishna D, Murty US, Sai KS: Impact of different housing structures on filarial transmission in rural areas of southern India. Southeast Asian J Trop Med Public Health 2004, 35:587-590.

113. Schofield CJ, White GB: House design and domestic vectors of disease. Trans R Soc Trop Med Hyg 1984, 78:285-292.

114. Webb DJ: Low-cost housing and parasite vectors. Parasitol Today 1985, 1:65-66.

115. Kirby MJ, Green C, Milligan PM, Sismanidis C, Jasseh M, Conway DJ, Lindsay SW: Risk factors for house-entry by malaria vectors in a rural town and satellite villages in The Gambia. Malar J 2008, 7:2.

116. Lindsay SW, Jawara M, Paine K, Pinder M, Walraven GE, Emerson PM: Changes in house design reduce exposure to malaria mosquitoes. Trop Med Int Health 2003, 8:512-517.

117. Lindsay SW, Emerson PM, Charlwood JD: Reducing malaria by mosquitoproofing houses. Trends Parasitol 2002, 18:510-514.

118. Lindsay SW, Snow RW: The trouble with eaves; house entry by vectors of malaria. Trans R Soc Trop Med Hyg 1988, 82:645-646.

119. Kampango A, Braganca M, Sousa B, Charlwood JD: Netting barriers to prevent mosquito entry into houses in southern Mozambique: a pilot study. Malar J 2013, 12:99.

120. Kirby MJ, Bah P, Jones CO, Kelly AH, Jasseh M, Lindsay SW: Social acceptability and durability of two different house screening interventions against exposure to malaria vectors, Plasmodium falciparum infection, and anemia in children in the Gambia, West Africa. Am J Trop Med Hyg 2010, 83:965-972.

121. Ogoma SB, Lweitoijera DW, Ngonyani H, Furer B, Russell TL, Mukabana WR, Killeen GF, Moore SJ: Screening mosquito house entry points as a potential method for integrated control of endophagic filariasis, arbovirus and malaria vectors. PLoS Negl Trop Dis 2010, 4:e773.

122. Ogoma SB, Kannady K, Sikulu M, Chaki PP, Govella NJ, Mukabana WR, Killeen GF: Window screening, ceilings and closed eaves as sustainable ways to control malaria in Dar es Salaam, Tanzania. Malar J 2009, 8:221.

123. Charlwood JD, Pinto J, Ferrara PR, Sousa CA, Ferreira C, Gil V, Do Rosario VE: Raised houses reduce mosquito bites. Malar J 2003, 2:45.

124. malERA Consultative Group on Integration Strategies: A research agenda for malaria eradication: cross-cutting issues for eradication. PLoS Med 2011, 8:e1000404.

125. Henderson DA: Eradication: lessons from the past. Bull World Health Organ 1998, 76(Suppl 2):17-21.

126. Kaneko A, Taleo G, Kalkoa M, Yamar S, Kobayakawa T, Bjorkman A: Malaria eradication on islands. Lancet 2000, 356:1560-1564.

127. Beier JC, Keating J, Githure JI, Macdonald MB, Impoinvil DE, Novak RJ: Integrated vector management for malaria control. Malar J 2008, 7(Suppl 1):S4.

128. Amoran OE, Fatugase KO, Fatugase OM, Alausa KO: Impact of health education intervention on insecticide treated nets uptake among nursing mothers in rural communities in Nigeria. BMC Res Notes 2012, 5:444.

129. Deribew A, Birhanu Z, Sena L, Dejene T, Reda AA, Sudhakar M, Alemseged F, Tessema F, Zeynudin A, Biadgilign S, Deribe K: The effect of household heads training about the use of treated bed nets on the burden of malaria and anaemia in under-five children: a cluster randomized trial in Ethiopia. Malar J 2012, 11:8.

130. Fatungase $\mathrm{KO}$, Amoran OE, Alausa KO: The effect of health education intervention on the home management of malaria among the caregivers of children aged under 5 years in Ogun State, Nigeria. Eur J Med Res 2012, 17:11.

131. Okeke TA: Improving malaria recognition, treatment and referral practices by training caretakers in rural Nigeria. J Biosoc Sci 2010, 42:325-339.

132. Ajayi IO, Oladepo O, Falade CO, Bamgboye EA, Kale O: The development of a treatment guideline for childhood malaria in rural Southwest Nigeria using participatory approach. Patient Educ Couns 2009, 75:227-237.

133. Yasuoka J, Poudel KC, Poudel-Tandukar K, Nguon C, Ly P, Socheat D, Jimba M: Assessing the quality of service of village malaria workers to strengthen community-based malaria control in Cambodia. Malar J 2010, 9:109.

134. Mukanga D, Babirye R, Peterson S, Pariyo GW, Ojiambo G, Tibenderana JK, Nsubuga $\mathrm{P}$, Kallander $\mathrm{K}$ : Can lay community health workers be trained to use diagnostics to distinguish and treat malaria and pneumonia in children? Lessons from rural Uganda. Trop Med Int Health 2011, 16:12341242.

135. Okeke TA, Uzochukwu BS: Improving childhood malaria treatment and referral practices by training patent medicine vendors in rural south-east Nigeria. Malar J 2009, 8:260.

136. Yasuoka J, Mangione TW, Spielman A, Levins R: Impact of education on knowledge, agricultural practices, and community actions for mosquito control and mosquito-borne disease prevention in rice ecosystems in Sri Lanka. Am J Trop Med Hyg 2006, 74:1034-1042.

137. Ediau M, Babirye JN, Tumwesigye NM, Matovu JKB, Machingaidze S, Okui O, Wanyenze RK, Waiswa P: Community knowledge and perceptions about indoor residual spraying for malaria prevention in Soroti district, Uganda: a cross-sectional study. Malar J 2013, 12:170.

138. Rodriguez AD, Penilla RP, Rodriguez MH, Hemingway J, Trejo A, Hernandez-Avila $J E$ : Acceptability and perceived side effects of insecticide indoor residual spraying under different resistance management strategies. Salud Publica Mex 2006, 48:317-324

139. Vundule C, Mharakurwa S: Knowledge, practices, and perceptions about malaria in rural communities of Zimbabwe: relevance to malaria control. Bull World Health Organ 1996, 74:55-60

140. Lacey LA, Orr BK: The role of biological control of mosquitoes in integrated vector control. Am J Trop Med Hyg 1994, 50:97-115.

141. Amoran OE: Impact of health education intervention on malaria prevention practices among nursing mothers in rural communities in Nigeria. Niger Med J 2013, 54:115-122

142. Rupp HR: Integrated mosquito management: no new thing. Emerg Infect Dis 2001, 7:761-762

143. Ayi I, Nonaka D, Adjovu JK, Hanafusa S, Jimba M, Bosompem KM, Mizoue T, Takeuchi T, Boakye DA, Kobayashi J: School-based participatory health education for malaria control in Ghana: engaging children as health messengers. Malar J 2010, 9:98

144. Nonaka D, Jimba M, Mizoue T, Kobayashi J, Yasuoka J, Ayi I, Jayatilleke AC, Shrestha S, Kikuchi K, Haque SE, Yi S: Content analysis of primary and secondary school textbooks regarding malaria control: a multi-country study. PLoS One 2012, 7:e36629.

145. Fullman N, Burstein R, Lim SS, Medlin C, Gakidou E: Nets, spray or both? The effectiveness of insecticide-treated nets and indoor residual spraying in reducing malaria morbidity and child mortality in sub-Saharan Africa. Malar J 2013, 12:62

146. Kleinschmidt I, Schwabe C, Shiva M, Segura JL, Sima V, Mabunda SJ, Coleman M: Combining indoor residual spraying and insecticide-treated net interventions. Am J Trop Med Hyg 2009, 81:519-524.

147. Atkinson JA, Fitzgerald L, Toaliu H, Taleo G, Tynan A, Whittaker M, Riley I, Vallely A: Community participation for malaria elimination in Tafea Province, Vanuatu: Part I. Maintaining motivation for prevention practices in the context of disappearing disease. Malar J 2010, 9:93.

148. Sharma VP: Re-emergence of malaria in India. Indian J Med Res 1996, 103:26-45.

149. Cohen JM, Smith DL, Cotter C, Ward A, Yamey G, Sabot OJ, Moonen B: Malaria resurgence: a systematic review and assessment of its causes. Malar J 2012, 11:122

doi:10.1186/1475-2875-13-140

Cite this article as: Yasuoka et al: Application of loop analysis for

evaluation of malaria control interventions. Malaria Journal 2014 13:140.

\section{Submit your next manuscript to BioMed Central and take full advantage of:}

- Convenient online submission

- Thorough peer review

- No space constraints or color figure charges

- Immediate publication on acceptance

- Inclusion in PubMed, CAS, Scopus and Google Scholar

- Research which is freely available for redistribution 